\title{
Ecosystem spatial structure revealed by integrated survey data
}

\author{
Petitgas Pierre ${ }^{1,{ }^{*}}$, Huret Martin ${ }^{4}$, Dupuy Christine ${ }^{2}$, Spitz Jérôme ${ }^{3}$, Authier Matthieu ${ }^{3}$, \\ Romagnan Jean-Baptiste ${ }^{1}$, Doray Mathieu ${ }^{1}$
}

1 IFREMER, unit EMH, BP 21105, 44311 cedex 03 Nantes, France

2 Université de La Rochelle, unité LIENSs, 2 rue Olympe de Gouges, 17000 La Rochelle, France

${ }^{3}$ Université de La Rochelle, unité PELAGIS, 2 rue Olympe de Gouges, 17000 La Rochelle, France

${ }^{4}$ IFREMER, unit STH, BP 70, 29280 Plouzané, France

* Corresponding author : Pierre Petitgas, email address : pierre.petitgas@ifremer.fr

\begin{abstract}
:
Integrated marine survey series such as PELGAS provide comprehensive geo-referenced data over large sea areas in major ecosystem components with defined biological resolution and spatio-temporal sampling scale. These data enable to develop product at different levels of biological organization and spatial scale that are useful for ecosystem integrated assessments. Using the PELGAS integrated data series, we applied a generic procedure made of several steps to identify and map ecologically coherent ecosystem spatial units in the Bay of Biscay. First, the data were interpolated on a common spatial grid and organized as a time series of matrices containing at each time the variables as columns and the grid cell values as rows. The multi-table analysis method known as Multi-Factor Analysis (MFA) was then applied on the series of matrices, thus separating in the analysis the spatial from the temporal variability. Grouping the spatial grid cells based on their relative positions in the MFA space resulted in mapping ecosystem spatial entities based on common spatial patterns across ecosystem components. The result of the analysis is a map of ecosystem seascapes that are consistent over the years together with a map of their inter-annual variability. The ecosystem sub-units were in agreement with subregional production systems in the Bay of Biscay. This study thus highlights the possibility to characterize and monitor ecosystem spatial structure and develop indicators thereof for their use in ecosystem assessments. Also, it highlights the importance of identifying spatial limits of production systems for ecosystem description, assessment and management.
\end{abstract}




\section{Highlights}

- Demonstrate how georeferenced integrated survey data series can be serve ecosystem description. - How ecosystem spatial structure can be revealed by applying Multiple Factor Analysis (MFA) on integrated survey data series. - How the same methodology also produces a map of temporal variability around the average ecosystem structure. The understanding of the Bay of Biscay as a meta-ecosystem made of connected distinct production systems sustaining pelagic fish resources.

Keywords : Integrated surveys, Ecosystems, Spatial structure, Multi-Factor Analysis, Bay of Biscay, Pelagic 


\section{Contents}

1. Introduction

2. Sampling protocols and data

Multidisciplinary survey design

Hydrology and Phytoplankton

Zooplankton

Pelagic fish

Top predators

3. Methods

Gridding the data

Multi Factor Analysis (MFA)

Selection of variables in each ecosystem compartment

MFA applied on all ecosystem compartments

Summary of the procedure applied

4. Results

Selection of variables in each ecosystem compartment

Common spatial patterns across ecosystem compartments and their variability

5. Discussion

Data and methods for ecosystem description and assessment

From seascapes to production systems and meta-ecosystems

Towards spatially explicit management scenarios

\section{Introduction}

The ecosystem approach to fisheries management (Garcia et al., 2003) implies understanding stock dynamics within ecosystems, conserving ecosystem structure and function, whilst considering multiple pressures from fishing and other human activities as well as climate drivers. Clearly, the implementation of an ecosystem approach to fisheries management requires the development of integrated assessment procedures across different spatial and temporal scales relevant to the scale of human pressures impacting upon various components of the marine ecosystems. In this context, integrated ecosystem assessments have developed (Kenny et al., 2009; ICES, 2016) to i) characterize past and present states of ecosystem components and functions, and ii) evaluate changes over time and how these link with particular drivers. Fisheries surveys are naturally an important data source for ecosystem description and identification of changes in ecosystem components over time. In 
effect, fisheries surveys, which were previously dedicated to support stock assessments, are now increasingly providing the basis for multidisciplinary integrated monitoring to assess the status and functions of ecosystems (Doray et al., this issue; Eriksen et al., this issue; Shephard et al., 2015).

Two challenges need be addressed for using integrated surveys to characterize the status of ecosystems: first, the technical ability to collect quasi-synoptically data in the main ecosystem components without changing the original fisheries survey sampling design (Doray et al., this issue) and secondly the spatio-temporal question of scale at which to collect meaningful data in the different compartments (Kupschus, 2016; Huret et al., this issue). Parameters in lower trophic levels can be expected to vary on different spatial and temporal scales in comparison to those at higher trophic levels including fish. Accordingly, the design of a survey whilst addressing variation adequately for one component may not be appropriate to make an assessment of all other ecosystem components of interest, e.g. can plankton data and the physical properties of the sea, sampled as part of a fisheries survey, be used jointly and inform appropriately ecosystem description and its assessment? The present study aims to address this question.

The PELGAS survey series (Doray et al., this issue; ICES, in press) is an integrated pelagic survey that collects data in the major components of the pelagic ecosystem (hydrology, phyto and zoo plankton, fish, top predators) over a large sea region (Biscay French shelf) during one month, day and night. The data collected are spatially resolved and thus offer the possibility to map ecosystem structure. The objective of the paper is to characterize the spatial structure of the ecosystem using the end-toend data collected during the survey. First the different variables collected in the different ecosystem components with different spatial resolutions are mapped at the same spatial scale. Then the time series of multiple maps is analysed using a multi-table methodology, Multi-factor analysis (MFA: Escoffier and Pagès, 1994; Dazy and Le Barzic, 1996; Abdi et al., 2013; Petitgas and Poulard, 2009). In this approach, the same variables are evaluated at the same locations and repeatedly at different times (years). The method quantifies, using Principal Components Analysis, the reproducibility in time of the multivariate spatial structure among all the data. To our knowledge, maps of ecosystem structure are seldom produced (ICES, 2016) while they are necessary for ecosystem assessments in the context of an ecosystem approach to fisheries management. Using PELGAS survey data series in the Bay of Biscay, this paper suggests a way forward for mapping ecosystem structure using georeferenced comprehensive data collected by integrated surveys.

\section{Sampling protocols and data}

\subsection{Multidisciplinary survey design}

The PELGAS sampling design combines en-route with at-station data collection strategies (Doray et al., 2014; ICES, in press; Doray et al., this issue). The survey takes place each year in May during 
spring and lasts one month. The en-route data concern higher trophic levels (fish and top predators) while the at-station data concern the hydrological water column structure and lower trophic levels (phyto- and zooplankton). En-route data are collected along a grid of regularly spaced transects 12 nautical miles $(\mathrm{nm})$ apart, which extend from the coast (20m bottom depth) to the shelf break $(250 \mathrm{~m})$. The survey lines are oriented perpendicular to the isobaths and are transited at 10 knots during day light hours. The grid is sampled annually at the same time of the year. Data collected simultaneously en-route are acoustic records of pelagic fish abundance, subsurface egg abundance pumped with CUFES (Continuous underway fish egg sampler) and visual counts of sea birds and mammals. At-station data are collected during hours of darkness, on a grid of stations positioned regularly along every second transect (10 to $20 \mathrm{~nm}$ apart). The same station positions are sampled annually. Data are collected simultaneously at each station by way of CTD vertical casts, which sample continuously and vertically temperature, salinity, and fluorescence. In addition Niskin bottles are used to measure chlorophyll a at depth (abundance by size class) and WP2 nets with $200 \mu \mathrm{m}$ mesh size provide an integrated sample of the water column for zooplankton (abundance by size class). This minimum protocol (more variables can be sampled in a given year) has been performed since 2009 and covers the entire shelf of the French part of the Bay of Biscay from $43.6^{\circ} \mathrm{N}$ to $48^{\circ} \mathrm{N}$ (Fig.1). The data series available for the study extends from 2009 to 2014.

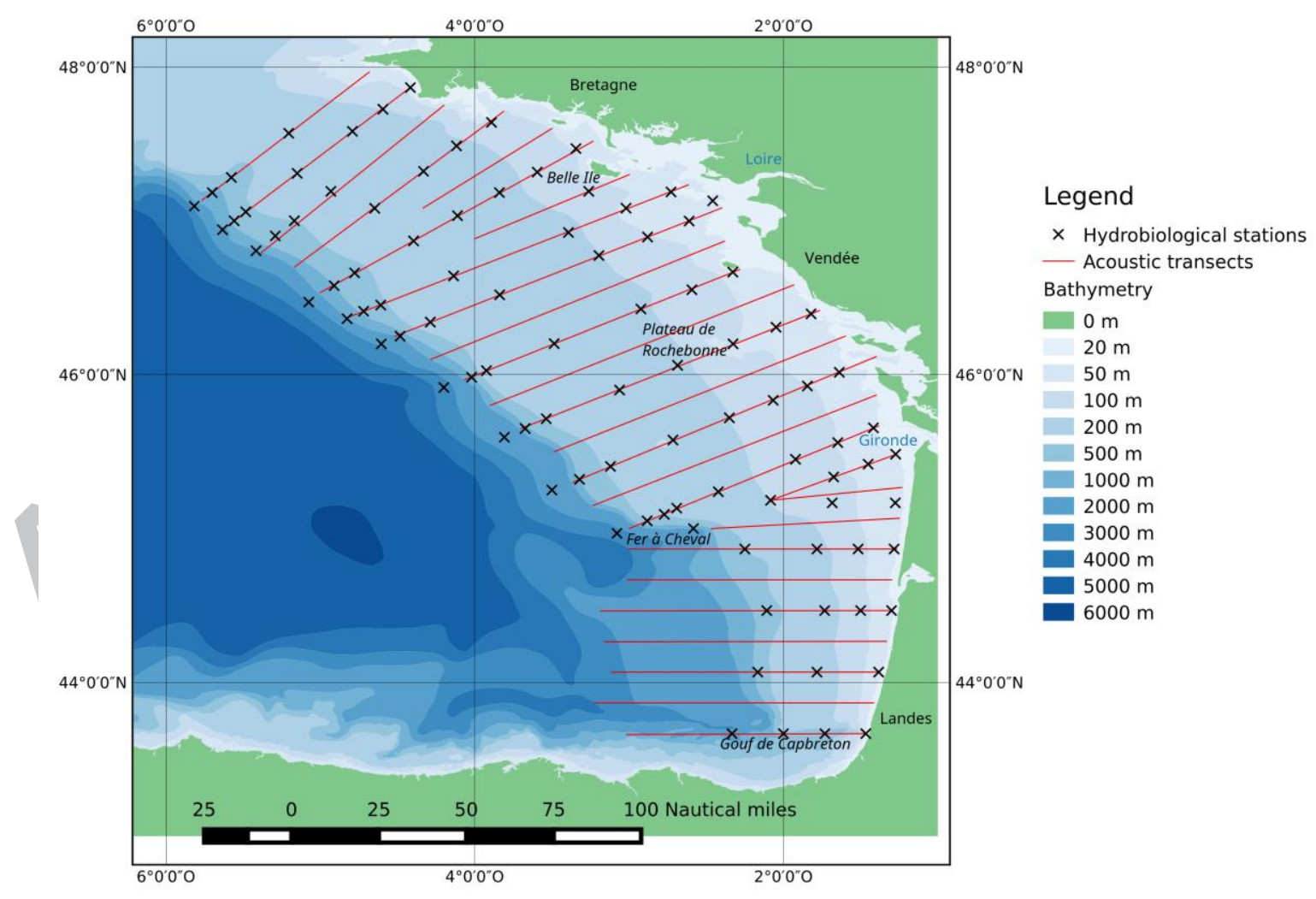

Figure 1: Map of PELGAS survey design over the French shelf of the Bay of Biscay showing the transects (red lines) for collecting data on pelagic fish and top predators during day-light hours and 
the stations (black crosses) for collecting depth-integrated data on hydrology and plankton during hours of darkness.

To characterize the pelagic ecosystem, we considered a list of variables to represent the following compartments: hydrology, phytoplankton, zooplankton, pelagic fish, sea birds and mammals. For hydrology we considered surface and bottom temperature, surface salinity and indices characterizing water column stratification. For phytoplankton, we considered vertically integrated chlorophyll_a abundance and size fractionated chlorophyll_a at surface. For zooplankton, we considered vertically integrated total abundance and size fractionated abundance. While lower trophic levels were characterized by total and size fractionated abundance, higher trophic levels were characterized by a selection of species, which are most consistently found in the series of surveys (Table 1). The fish species were anchovy (Engraulis encrasicolus), sardine (Sardina pilchardus), sprat (Sprattus sprattus), two mackerel species (Scomber scombrus and Scomber japonicus) and horse mackerel (Trachurus trachurus). Top predator species were aggregated in groups with common ecology: auks, gannets, gulls and terns, large and small delphinids.

Table 1: List of variables characterizing the pelagic realm, which are derived from the PELGAS integrated survey design and protocol

\begin{tabular}{|c|c|}
\hline Ecosystem compartment & Variable used \\
\hline Hydrology & $\begin{array}{l}\text { ST: Surface temperature }\left({ }^{\circ} \mathrm{C}\right) \\
\text { BT: Bottom temperature }\left({ }^{\circ} \mathrm{C}\right) \\
\text { SS: Surface salinity (psu) } \\
\text { Heq: Height of equivalent freshwater depth }(\mathrm{m}) \\
\text { Depot: Deficit of potential energy }\left(\mathrm{kg} \mathrm{m}^{-1} \mathrm{~s}^{-2}\right) \\
\text { Zpyc: Depth of pycnocline }(\mathrm{m})\end{array}$ \\
\hline Phytoplankton & $\begin{array}{l}\text { CHLint: Vertically integrated Chlorophyll a }\left(\mathrm{mg} \mathrm{m}^{-2}\right) \\
\text { CHLS : Surface chlorophyll a }\left(\mathrm{mg} \mathrm{m}^{-3}\right) \\
\text { CHLS1: Surface chlorophyll a in cells }<3 \mu \mathrm{m}\left(\mathrm{mg} \mathrm{m}^{-3}\right) \\
\text { CHLS2: Surface chlorophyll a in cells } 3-20 \mu \mathrm{m}\left(\mathrm{mg} \mathrm{m}^{-3}\right) \\
\text { CHLS3: Surface chlorophyll a in cells }>20 \mu \mathrm{m}\left(\mathrm{mg} \mathrm{m}^{-3}\right)\end{array}$ \\
\hline Zooplankton & $\begin{array}{l}\text { Zmeso: Total dry weight of mesozooplankton }\left(\mathrm{mg} \mathrm{m}^{-2}\right) \\
\text { Z200: Dry weight of zooplankton between } 200-500 \mu \mathrm{m}\left(\mathrm{mg} \mathrm{m}^{-2}\right) \\
\text { Z500: Dry weight of zooplankton between 500-1000 } \mu \mathrm{m}\left(\mathrm{mg} \mathrm{m}^{-2}\right) \\
\text { Z1000: Dry weight of zooplankton between } 1000-2000 \mu \mathrm{m}\left(\mathrm{mg} \mathrm{m}^{-2}\right)\end{array}$ \\
\hline
\end{tabular}




\begin{tabular}{|l|l|}
\hline & Z2000: Dry weight of zooplankton $>2000 \mu \mathrm{m}\left(\mathrm{mg} \mathrm{m}^{-2}\right)$ \\
\hline Fish & ENGRENC : Anchovy $\left(10^{3} \mathrm{~kg} \mathrm{~nm}^{-2}\right)$ \\
& SARDPIL : Sardine $\left(10^{3} \mathrm{~kg} \mathrm{~nm}^{-2}\right)$ \\
& SPRASPR : Sprat $\left(10^{3} \mathrm{~kg} \mathrm{~nm}^{-2}\right)$ \\
& SCOMSO : Atlantic mackerel $\left(10^{3} \mathrm{~kg} \mathrm{~nm}^{-2}\right)$ \\
& SCOMJAP : Chub mackerel $\left(10^{3} \mathrm{~kg} \mathrm{~nm}^{-2}\right)$ \\
& TRACTRU : Horse mackerel $\left(10^{3} \mathrm{~kg} \mathrm{~nm}^{-2}\right)$ \\
\hline Top predators & AUK: Auks (number $\left.\mathrm{km}^{-2}\right)$ \\
& GAN: Gannets (number $\left.\mathrm{km}^{-2}\right)$ \\
& GULT: Gulls and terns (number $\left.\mathrm{km}^{-2}\right)$ \\
& DEL1: Small delphinids (number $\left.\mathrm{km}^{-2}\right)$ \\
& DEL2: Large delphinids (number $\left.\mathrm{km}^{-2}\right)$ \\
\hline
\end{tabular}

\subsection{Hydrology and phytoplankton}

Sampling the water column for hydrology and phytoplankton parameters is performed at night at stations with a conductivity-temperature-depth (CTD, SeaBird SBE19+V2) probe instrumented with a Wetlab fluorimeter. Vertical casts provide temperature, salinity, density and fluorescence throughout the water column. In addition, Niskin bottles provided water samples at three different depths: below thermocline, within the chlorophyll maximum and at surface. Water samples were filtered for size-fractionated $(<3 \mu \mathrm{m}, 3 \mu \mathrm{m}<<20 \mu \mathrm{m},>20 \mu \mathrm{m})$ estimations of chlorophyll concentration performed by spectrophotometry in the laboratory. From the CTD profiles, several hydrological indices are computed following equations of Huret et al. (2013): Surface temperature and surface salinity (between 2 and $7 \mathrm{~m}$ ), bottom temperature (with max depth set at $200 \mathrm{~m}$ ), equivalent water height and deficit of potential energy. The deficit of potential energy is an index of water column stratification corresponding to the energy that would be required to homogenize density over the column (with max depth set at $60 \mathrm{~m}$ ). The equivalent water height is an index of river plume influence on the shelf integrating over the water column the relative difference in salinity from a reference value set at 35.5. In comparison to surface salinity, this index relates better to the history of river run offs and vertical mixing. The integrated chlorophyll concentration is calculated by summing values over the water column profils using a fluorimeter, after correcting for potential bias by comparison to laboratory measurements of chlorophyll. This is done by regressing the fluorimeter values on the chlorophyll values at depth, all depths pooled. This post-calibration is performed by year.

\subsection{Zooplankton}


Mesozooplankton samples are collected during the night by operating a WP2 net (mouth opening of $0.25 \mathrm{~m}^{2}$ and mesh size of $200 \mu \mathrm{m}$ ). The net is hauled vertically from bottom (max depth set at $100 \mathrm{~m}$ ) to surface. When present macrozooplankton is eliminated by sieving the sample through a $5 \mathrm{~mm}$ mesh. Four size-classes of mesozooplankton are obtained by successive filtrations (washed with distilled water) on three sieves with mesh size 200, 500, 1000 and $2000 \mu \mathrm{m}$. Samples are frozen and stored at $-20^{\circ} \mathrm{C}$ until further analysis in the laboratory, where dry weight of size fractions are measured, the sum of which estimates total dry wet.

\subsection{Pelagic fish}

Fish abundance by species is derived from combining the acoustic records interpreted as fish echotraces with pelagic trawl haul samples following standard acoustic multi-species procedure (Petitgas et al., 2003; Doray et al., 2014 and references there in). Acoustic data are recorded en-route by day along transects at multiple frequencies, using Simrad ER60 hull-mounted calibrated echosounders. Pelagic trawl hauls are undertaken adaptively depending on the echotraces to inform on the species composition and their biological parameters (length, weight, age). Biomass estimation is performed using the $38 \mathrm{kHz}$ frequency data only while other frequencies are used to help isolate the fish echotraces from other echoes (e.g., sound scattering layers). Echograms are manually corrected for bottom detection errors then echo-integrated over standard depth layers $(10 \mathrm{~m})$ and one nautical mile $(\mathrm{nm})$ sailed distance (Elementary sampling distance unit: ESDU). Echograms are further scrutinized by experts to allocate previous echo-integrals into several echo categories (echotypes). The resulting data are Nautical area backscattering coefficients (NASC) by echo-type by nm along transects. For species identification, the NASC value for each echo-type in each ESDU is associated by experts to one identification trawl haul. The echo-type NASC value is then apportioned into a NASC per species using standard acoustic multi-species equations (Doray et al., 2014 and references there in). Finally the species-specific NASC values are further converted to biomass per species using the target strength (TS) corresponding to the mean length and weight of the species in the catch. This procedure results in estimating biomass per species (tonnes) for every nautical mile along transects.

\subsection{Top predators}

Sighting data of marine mammals and seabirds are collected en-route by day along transects by three observers following a standard distance sampling protocol (Doray et al., 2014 and references there in). The GPS location of each sighting is recorded. Two observers are positioned each on one side of the vessel, on the upper bridge ( $16 \mathrm{~m}$ above sea level) or inside the bridge (14 $\mathrm{m}$ above sea level) depending on weather conditions. Observations of megafauna is by eye within an angle of $90^{\circ}$ from 
the side to the bow. Binoculars are used for species identification following initial detection by eye. Identification is carried out to the lowest possible taxonomic level. Photos are systematically taken to validate species identification for cetaceans and seabirds. Every hour one observer is relieved from duty by the third one to limit observer fatigue. Counts are estimated as number of individuals per $\mathrm{km}^{2}$ and located in the middle of $2 \mathrm{~km}$ segments (elementary sampling units) along transects.

\section{Data Analysis}

The method proposed to analyze the multivariate and spatio-temporal structure in the data combines a gridding procedure with a multi-table analysis, in which spatial and temporal variability are separated.

\subsection{Gridding the data}

The data were mapped using a grid and an automated gridding procedure. When multiple values of the same variable were in the same grid cell these were averaged (Petitgas et al., 2009; ICES, in press). The grid mesh size selected was 0.25 degrees in latitude and longitude with origin $\mathrm{x}_{0}$ at $43^{\circ} \mathrm{N}$ and $6^{\circ} \mathrm{W}$. This choice resulted from a compromise between the number of variable values averaged in each grid cell, and the grid spatial resolution. For each variable, the mean of the grid cell $\left(i, j, x_{0}\right)$ was the average of the data inside the grid cell, positioned at the grid cell center. The gridded data depended on the grid origin. To decondition the gridded values from the grid origin, the point origin $x_{0}$ was randomized in the lowest left corner grid cell one 100 times. The 100 values computed within each grid cell were finally averaged to provide the grid cell value.

\subsection{Multi Factor Analysis (MFA)}

Multi Factor Analysis (MFA) is an extension of Principle Components Analysis (PCA) using multiple tables for the analysis of 3-dimensionally structured data (Escoffier and Pagès, 1994; Dazy and Le Barzic, 1996; Abdi et al., 2013). MFA is designed for situations where the same variables (matrix columns) are measured in the same grid cells (data rows) at various times (tables). In the MFA analysis, variability in time is explicitly differentiated from the correlation structure among the variables. This allows an estimate of the correlation structure among the variables that is most consistent in time and also to quantify the temporal variability around the average structure. In single PCA all sources of variability are pooled and thus the spatial and temporal structures are less clearly identified than in MFA. When using MFA, the data are structured as a time series of elementary tables. For a given survey (year), the elementary table contains the variables in columns and the grid cell values in rows. The data are organized as a time series of such tables, one per year. MFA proceeds as a double PCA. First, a PCA is applied to each yearly table, where columns are 
centered and normed. Each table is then further normalized by its first eigen value, which allows to compare all tables. For that, a second PCA is applied on the global table made of the normalized tables appended by columns. In doing so MFA constructs a factorial space that is a compromise between all elementary (normalized) tables, in which the 3-dimensional structure of the data is represented. In particular, each grid cell (table row) is represented by $n$ points ( $\mathrm{n}$ years) in the MFA space and so is each variable (table column). Further, the principal components of the MFA are interpretable using their correlation with the variables. Each variable having $\mathrm{n}$ point positions ( $\mathrm{n}$ years) in the MFA space, the MFA principle components are interpreted with those variables showing a good correlation with the components for a sufficiently large number of years. Being based on PCA, MFA suffers the same limitations as PCA. In particular, all variables must be valued in all grid cells and the correlation between variables may be affected by a large proportion of zeroes and/or very high values. The gridding procedure reduces here these effects by smoothing. Also transforming the grid cell means may reduce the effect of some high values on the correlations. MFA has been applied in fisheries science to characterize seasonal and inter-annual variations in fish community structures (Gaertner et al., 1998), fishing activities (Poulard and Léauté, 2002) or monitoring in time the spatial structure in fish populations (Petitgas et al., 2009). Here to apply MFA, we used the library ade4 in R language (Dray and Dufour, 2007) and in particular the function $\mathrm{mfa}($ ) with option 'lambda1'. The biological variables were $\log (x+1)$ transformed and the hydrological variable were not.

\subsection{Selection of variables in each ecosystem compartment}

MFA was first applied to each ecosystem compartment using the variables characterizing that compartment (Table 1). Variables were selected based on their repeated good correlation with the MFA principal components for a sufficient number of years. In effect, variables selected on that criteria carry the structure among the variables that is most consistent across the series of years (2009-2014). The variables retained had correlation coefficients with at least one of the two first principal components that were greater than 0.5 in absolute value and for which such (good) correlation occurred with a frequency in time higher than 0.5. Correlation of variables with principal components of higher order $(>2)$ was often low or infrequent, meaning that these components were difficult to interpret and this is why we used the first two principal components only. Some variables were redundant as they showed similar correlation with the MFA principal components. In that case and in order to select one variable only among the redundant ones, we analyzed the sensitivity of each of the redundant variables in the global analysis. The full analysis was run considering each variable at a time and without the other redundant ones. The variable selected was the one which allowed the most clear-cut clustering among grid cell points (see below). This approach selected variables in one ecosystem compartment that correlated well with other variables in other 
compartments. The variables finally selected carried so to speak the correlation structure for their compartment that was the most consistent over the years as well as across compartments. The selection procedure thus reduces noise and allows to better identify the overall structure across ecosystem compartments.

\subsection{MFA applied on all ecosystem compartments}

MFA was then applied to all selected variables representing best their ecosystem compartment. Those variables, which had with the MFA principal components correlation coefficients greater than 0.5 in absolute value for more than half of the years, were identified as those carrying the main structure of the ecosystem. The positions of the grid cells in the MFA space served to map ecosystem structure and characterized variability between years around the average map. A hierarchical clustering (function hclust in $\mathrm{R}$ language) was performed on the average grid points. Cutting the hierarchical tree at appropriate level allowed to group the grid cell points into a few classes, which were then mapped. The clusters of grid cell points represented particular regions in the Bay of Biscay, thus revealing sub-systems or seascapes. For each grid cell, the squared distance in the MFA space between its annual position and its mean position summed over the years represented the inertia of that grid cell and characterized inter-annual variability, which was also mapped. The inertia at geographical location $\mathrm{x}$ writes:

$$
I(x)=\sum_{k=1}^{n} \operatorname{dist}^{\wedge} 2(p(x, k), p m(x))
$$

Where $x$ is a grid cell center, $k$ the index of the years, $p(x, k)$ the point in the MFA space representing grid point $\mathrm{x}$ in year $\mathrm{k}$ and $\mathrm{pm}$ the point in the MFA space representing the average grid point. The squared distance dist^ 2 was computed using coordinates of points $p(x, k)$ and $p m(x)$ on the two first MFA principal components. Similarly, the inertia for each variable was computed to quantify interannual variability in each of the variables.

\subsection{Summary of the procedure applied}

In summary we suggest here a procedure to analyze data from fisheries integrated surveys. The data are geo-referenced and correspond to repeated measurements in time (e.g., each year) of the same variables in major ecosystem compartments. The different steps of the procedure are the following:

- Data gridding. The data are mapped on the same grid providing a series of maps. There are as many maps as years. Each map is a table where the rows are the grid cell values and the columns the variables measured; 
- Selection of variables in each ecosystem compartment. This step results is a list of variables, which carry the multivariate structure that is most consistent in time in each ecosystem compartment and also across compartments;

- MFA on all ecosystem compartments using selected variables. This provides a description of the ecosystem multivariate and spatial structure that is consistent in time as well as a quantification of the temporal variability around the average structure. Hierarchical clustering of the grid cell points in the MFA space allows to map ecosystem structure. And computing in the MFA space the inertia in time allows to map ecosystem variability around the average structure.

An example R script is provided as supplementary material together with gridded data from the Pelgas survey series, allowing to apply MFA on this example data set to perform the last step of the above procedure.

\section{Results}

\subsection{Selection of variables in each ecosystem compartment}

MFA was applied in each ecosystem compartment on the series 2009-2014 (see Table 1 for the list of variables by compartment). The first two principal components in each compartment explained between 45-62 percent of the space-time variability, Phytoplankton and Pelagic Fish compartments showing the less explained variability (Figure 2). 


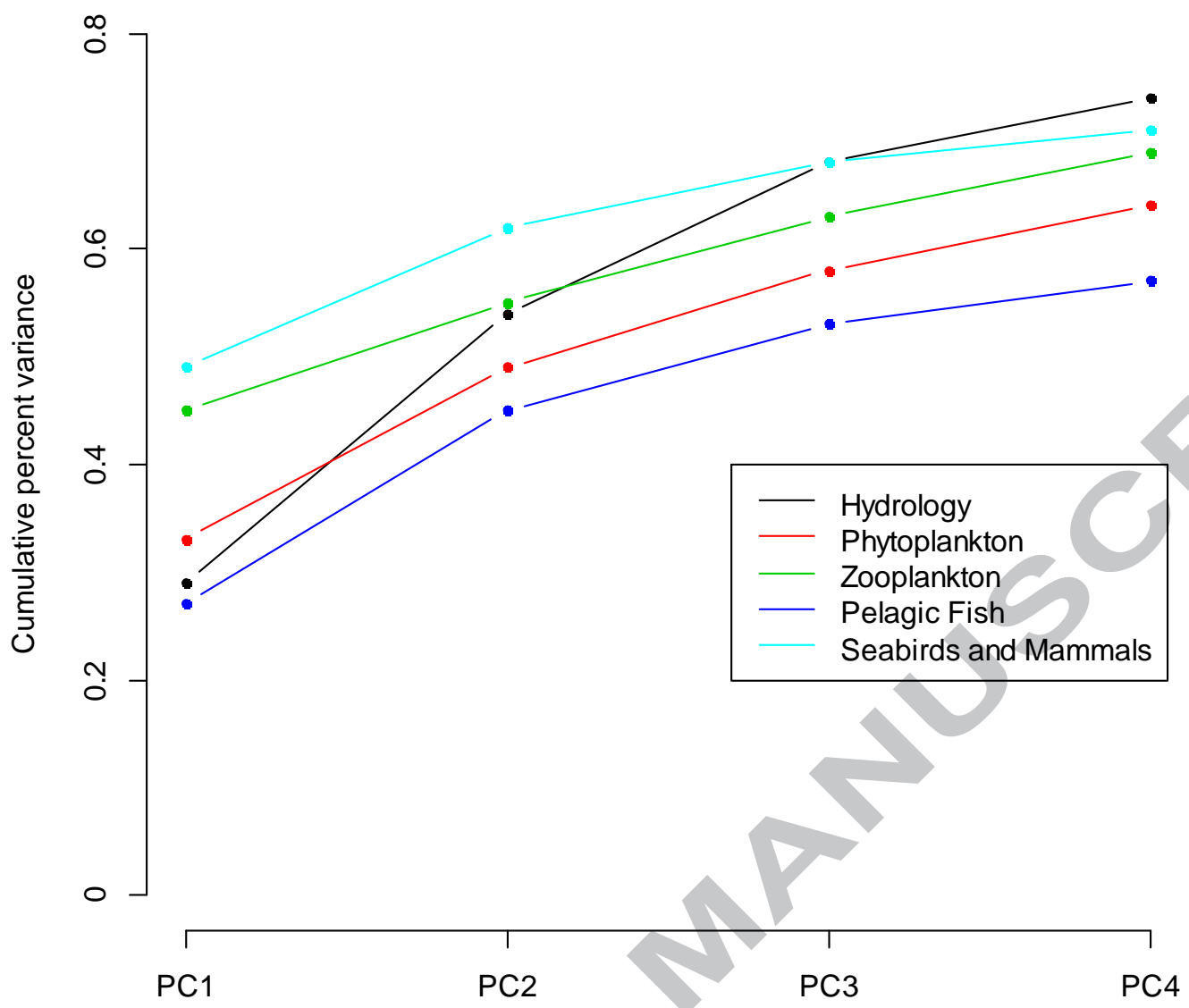

Figure 2: Cumulated percent variance explained by the first four MFA principal components, when applying MFA in each ecosystem compartment on the series 2009-2014 of the gridded data.

The frequency in time of the correlation of the variables with the MFA components (Table 3) allowed to select those variables representing best the space-time variability in their ecosystem compartment. For a few variables only, we considered their sensitivity in the global analysis. In the Phytoplankton compartment, Total surface chlorophyll and Chlorophyll in cells greater than $20 \mu \mathrm{m}$ were redundant but we finally selected Total surface chlorophyll, which was also less statistically variable. Similarly in the Zooplankton compartment, biomasses in the fractions greater than $1000 \mu \mathrm{m}$ and $2000 \mu \mathrm{m}$ were redundant and we selected the fraction greater than $1000 \mu \mathrm{m}$, which was also less statistically variable. In the Seabirds and Mammals compartment Gannets and Gulls were redundant and neither was selected. These species were largely distributed on the entire shelf, which decreased the efficiency of the clustering in the global analysis. Chub mackerel in the Fish compartment was close to be selected using the correlation criteria. This variable was mainly distributed in the South $\left(<45.5^{\circ}\right)$ but with high variability among years in its location. When selected, it also decreased the efficiency of the clustering in the global analysis. Finally 13 variables were 
retained (Table 4), which summarized spatial patterns in their compartments that were consistent in time: 3 for Hydrology, 2 for Phytoplankton, 2 for Zooplankton, 3 for Fish and 3 for Top predators.

Table 3: Number of years, in which the variables were correlated with the first four principal components of (partial) MFA applied in each ecosystem compartment. The time series was from 2009 to 2014 . The notation " $n+\mid k-“$ indicates $n$ positive and k negative correlations. Correlations with absolute value greater than 0.5 were considered only. Acronyms of variable are defined in Table 1. The column Selection indicates whether or not the variable was selected for applying MFA on all ecosystem compartments.

\begin{tabular}{|c|c|c|c|c|c|c|}
\hline & Variables & Corr. PC1 & Corr. PC2 & Corr. PC3 & Corr. PC4 & Selection \\
\hline \multirow[t]{6}{*}{ Hydrology } & ST & $0+10-$ & $3+10$ & $3+10-$ & $0+11-$ & No \\
\hline & BT & $4+10-$ & $3+10$ & $0+10-$ & $0+10-$ & Yes \\
\hline & SS & $0+\mid 4-$ & $3+10$ & $0+11-$ & $0+10-$ & Yes \\
\hline & Heq & $3+10-$ & $0+13-$ & $2+10-$ & $0+10-$ & No \\
\hline & Depot & $0+\mid 4-$ & $0+10-$ & $4+10-$ & $0+10-$ & Yes \\
\hline & Zpyc & $0+\mid 4-$ & $0+11-$ & $0+10-$ & $0+10-$ & No \\
\hline \multirow[t]{5}{*}{ Phytoplankton } & CHLint & $1+10-$ & $5+10-$ & $0+10-$ & $0+10$ & Yes \\
\hline & CHLS & 0 & $1+\mid 0-$ & $1+\mid 0-$ & $0+10-$ & Yes \\
\hline & CHLS1 & $0+1$ & $0+10-$ & $0+\mid 1-$ & $0+10-$ & No \\
\hline & CHLS2 & $0+13-$ & $1+\mid 0-$ & $0+10-$ & $1+10-$ & No \\
\hline & CHLS3 & $0+15-$ & $1+\mid 0-$ & $0+10-$ & $0+10-$ & No \\
\hline \multirow[t]{5}{*}{ Zooplankton } & Zmeso & $0+16-$ & $0+\mid 1-$ & $0+\mid 1-$ & $1+10-$ & Yes \\
\hline & Z200 & $0+10-$ & $1+1-$ & $0+\mid 1-$ & $0+1-$ & No \\
\hline & $Z 500$ & $0+15-$ & $0+\mid 1-$ & $0+10-$ & $0+10-$ & No \\
\hline & Z1000 & $0+16-$ & $0+10-$ & $0+10-$ & $0+10-$ & Yes \\
\hline & Z2000 & $0+16-$ & $0+10-$ & $0+10-$ & $0+10-$ & No \\
\hline \multirow{6}{*}{ Pelagic Fish } & ENGRENC & $0+\mid 5-$ & $0+10-$ & $0+\mid 1-$ & $0+10-$ & Yes \\
\hline & SARDPIL & $0+16-$ & $0+10$ & $0+10$ & $0+10-$ & Yes \\
\hline & SPRASPR & $0+\mid 4-$ & $0+12-$ & $0+10-$ & $0+10-$ & Yes \\
\hline & SCOMSO & $1+\mid 0-$ & $1+\mid 0-$ & $0+\mid 0-$ & $0+\mid 1-$ & No \\
\hline & SCOMJAP & $0+10-$ & $3+10-$ & $0+10-$ & $0+10-$ & No \\
\hline & TRACTRU & $2+10-$ & $1+\mid 0-$ & $0+10-$ & $0+10-$ & No \\
\hline \multirow{2}{*}{$\begin{array}{l}\text { Seabirds and } \\
\text { Mammals }\end{array}$} & AUK & $0+16-$ & $5+10-$ & $1+\mid 0-$ & $0+10-$ & Yes \\
\hline & GAN & $0+\mid 5-$ & $0+10-$ & $0+10-$ & $0+11-$ & No \\
\hline
\end{tabular}




\begin{tabular}{|l|l|l|l|l|l|l|}
\hline & GULT & $0+\mid 6-$ & $0+\mid 0-$ & $0+\mid 0-$ & $0+\mid 0-$ & No \\
& DEL1 & $5+\mid 0-$ & $6+\mid 0-$ & $0+\mid 0-$ & $0+\mid 0-$ & Yes \\
& DEL2 & $6+\mid 0-$ & $0+\mid 0-$ & $0+\mid 0-$ & $0+\mid 0-$ & Yes \\
\hline
\end{tabular}

\subsection{Common spatial patterns across ecosystem compartments and their variability}

MFA was applied on all ecosystem compartments using the 13 variables selected in section 4.1 (Table 3). The summed percent variance explained by the four first principal components were $0.31,0.51$, 0.59 and 0.65 respectively, which is close to what MFA explained in each compartment (Fig. 2), meaning that the spatial structures in the different compartments had broad similarities at the scale and resolution of this study. This is confirmed by the fact that 3 variables only (integrated chlorophyll, total mesozooplankton and small delphinids) were not well correlated with the principal components (Table 4).

Table 4: MFA on all ecosystem compartments using the 13 selected variables. Number of years, in which the variables were correlated with the MFA four first principal components. The time series was from 2009 to 2014 . The notation " $\mathrm{n}+\mathrm{k}-$ " indicates $\mathrm{n}$ positive and k negative correlations. Correlations with absolute value greater than 0.5 were considered only. Acronyms of variable are defined in Table 1.

\begin{tabular}{|l|l|c|c|c|c|}
\hline & Variables & Corr. PC1 & Corr. PC2 & Corr. PC3 & Corr. PC4 \\
\hline Hydrology & BT & $0+\mid 1-$ & $6+\mid 0-$ & $0+\mid 0-$ & $0+\mid 0-$ \\
& SS & $0+\mid 6-$ & $0+\mid 0-$ & $0+\mid 0-$ & $0+\mid 0-$ \\
& Depot & $0+\mid 0-$ & $0+\mid 4-$ & $3+\mid 0-$ & $0+\mid 0-$ \\
\hline Phytoplankton & CHLint & $0+\mid 2-$ & $0+\mid 0-$ & $0+\mid 1-$ & $0+\mid 1-$ \\
& CHLS & $4+\mid 0-$ & $0+\mid 0-$ & $0+\mid 1-$ & $0+\mid 0-$ \\
\hline Zooplankton & Zmeso & $0+\mid 3-$ & $0+\mid 3-$ & $0+\mid 0-$ & $0+\mid 0-$ \\
& Z1000 & $0+\mid 6-$ & $0+\mid 3-$ & $0+\mid 0-$ & $0+\mid 0-$ \\
\hline Pelagic Fish & ENGRENC & $1+\mid 0-$ & $5+\mid 0-$ & $0+\mid 0-$ & $0+\mid 1-$ \\
& SARDPIL & $6+\mid 0-$ & $0+\mid 0-$ & $0+\mid 0-$ & $0+\mid 0-$ \\
& SPRASPR & $5+\mid 0-$ & $0+\mid 0-$ & $0+\mid 0-$ & $0+\mid 0-$ \\
\hline Seabirds and & AUK & $6+\mid 0-$ & $0+\mid 0-$ & $0+\mid 0-$ & $0+\mid 0-$ \\
Mammals & DEL1 & $0+\mid 0-$ & $1+\mid 0-$ & $0+\mid 0-$ & $0+\mid 1-$ \\
& DEL2 & $0+\mid 5-$ & $2+\mid 0-$ & $0+\mid 0-$ & $0+\mid 0-$ \\
\hline
\end{tabular}


The spatial grid cells were grouped by applying hierarchical clustering in the MFA space. The similarity distance considered for grouping grid cells was the squared Euclidian distance between cells and it was computed using their average scores on the two first principal MFA components. Four groups were identified visually corresponding to a clear decline in dissimilarity (Fig. 3).

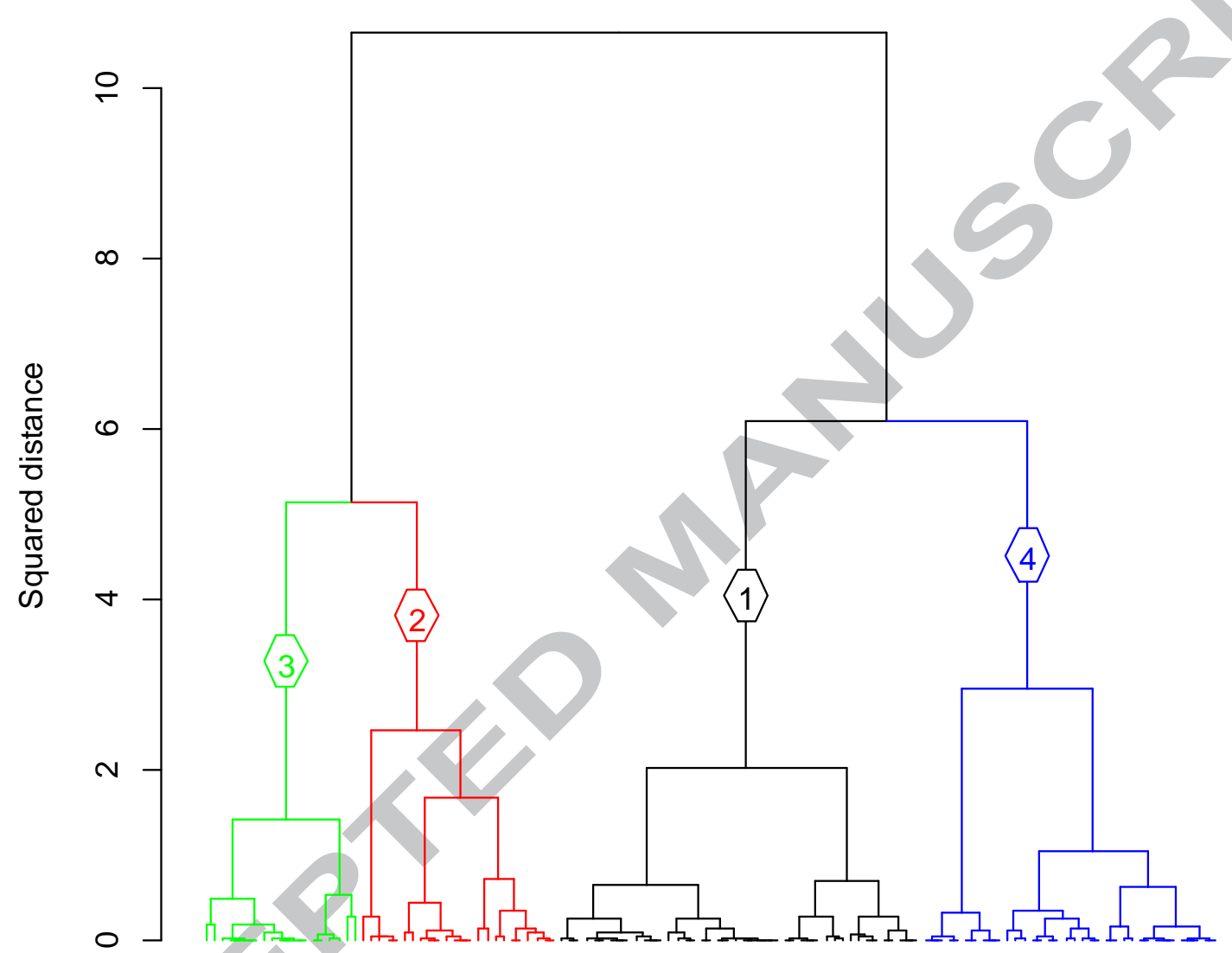

Figure 3: Cluster dendogram of grid cells obtained by their hierarchical clustering in the MFA space. The distance considered is the squared Euclidian distance between average grid cell points in the MFA plane made of the first two principal components. Four clusters were retained, which are shown in different colors.

The four (spatial) groups of grid cells were interpreted by identifying the variables, which characterized them best. For that we computed in each group the average variable value per year and looked for higher/lower values. In the analysis the variables are centered and normed. Thus the average per group per year is a residual variation for that group and year (Fig. 4). Group G1 was characterized by higher salinity and higher abundance of large delphinids and lower abundance of surface chlorophyll, sprat, sardine and auks. In contrast to G1, group G3 was characterized by lower salinity, higher abundance of surface chlorophyll, sprat, sardine and auks and lower abundance of 
large zooplankton and delphinids. Group G2 was characterized by higher bottom temperature, higher abundance of anchovy and sardine and lower abundance of large zooplankton. In contrast to G2, group G4 was characterized by lower bottom temperature, lower anchovy abundance and greater water column stratification and greater abundance of large zooplankton.

G1

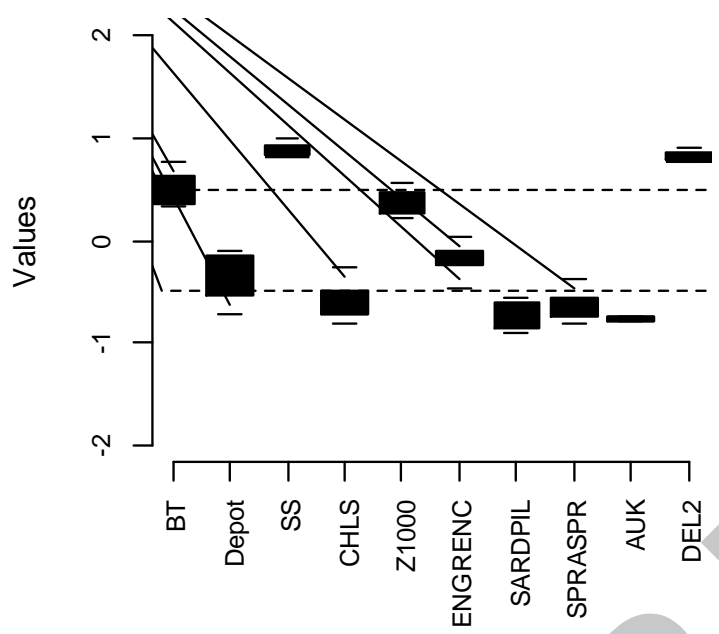

G3

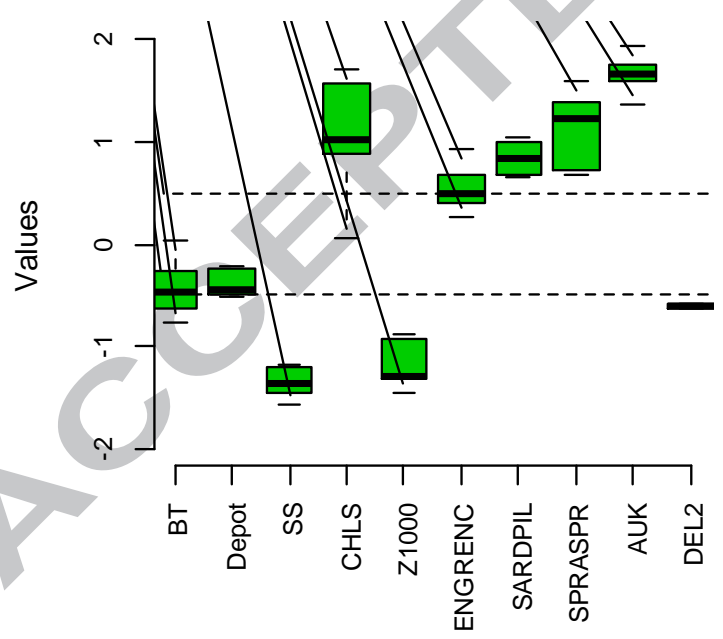

G2

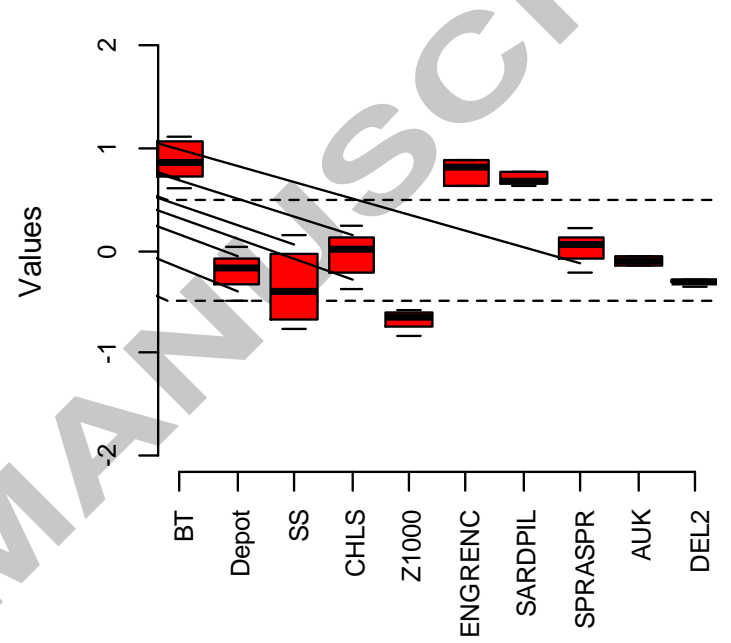

G4

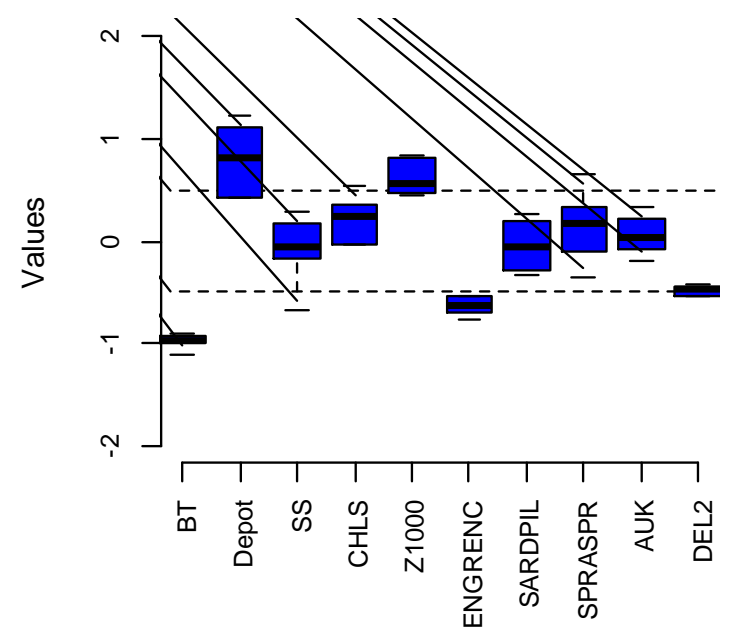

Figure 4: Variables values in each group (G1 to G4) of the spatial grid cells identified by hierarchical clustering. There is one average value per year per group for each variable allowing the inter-annual variability to be represented in boxplots. The variables being centered and normed, the horizontal dash lines are drawn for -0.5 and +0.5 standard deviation. Acronyms of variables are defined in Table 1. 
The clusters of grid cells were mapped, showing a strong spatial pattern revealing the Bay of Biscay seascapes (Fig. 5), which corresponded to the common spatial structure across ecosystem compartments.

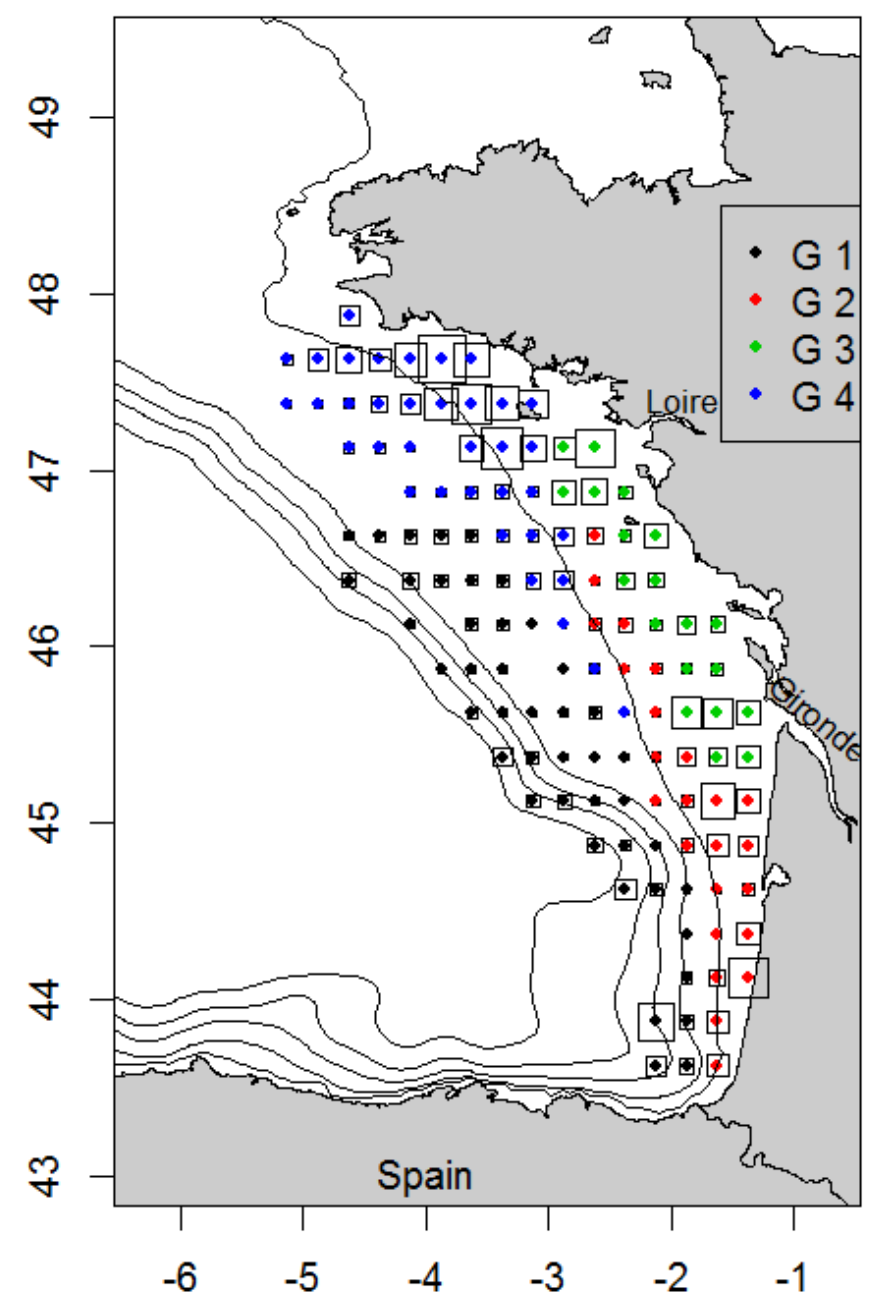

Figure 5: Map of Bay of Biscay seascapes as identified by applying MFA on all ecosystem compartments. Map of grid cell clusters and their variability in time over the years 2009-2014. Colors are that of the clusters (Fig. 3). Squares are proportional to the variability in time at each grid point (inertia). The isobaths are 100, 200, 500, 1000, $2000 \mathrm{~m}$.

Group G1 is located (Fig. 5) on the shelf-break and outer-shelf (bottom depth > $120 \mathrm{~m}$ ) while group G3 is located in the coastal and inner-shelf waters (bottom depth $<80 \mathrm{~m}$ ) from the Gironde to the Loire estuaries occupying the mid-latitudes in Biscay. Group G2 is located mainly over the southern 
shelf (latitude $<45^{\circ} \mathrm{N}$ ) while Group G4 is a northern Biscay group (latitude $>46^{\circ} \mathrm{N}$ ) centered on isobath $100 \mathrm{~m}$. The spatial organization and multivariate characteristics of the groups identified are summarized in Table 5. Some variables showed opposition across groups: surface salinity, large zooplankton, anchovy and sprat have higher values in particular groups and lower in others.

Table 5: Summary of the multivariate characteristics of the spatial clusters. Acronyms of variables are defined in Table 1.

\begin{tabular}{|l|l|l|}
\hline Group & Higher than mean & Lower than mean \\
\hline G1 (shelf-break) & SS & $\begin{array}{l}\text { CHLS } \\
\text { SARDPIL, SPRASPR } \\
\text { AUK }\end{array}$ \\
& DEL2 & SS \\
G3 (coastal at mid-latitude) & $\begin{array}{l}\text { CHLS } \\
\text { SARDPIL, SPRASPR } \\
\text { AUK }\end{array}$ & $\begin{array}{l}\text { DEL2 } \\
\text { G2 (southern shelf) }\end{array}$ \\
& BT & Z1000 \\
& ENGRENC, SARDPIL & BT \\
\hline G4 (northern shelf) & Depot & ENGRENC \\
& Z1000 & \\
\hline
\end{tabular}

In the MFA space, each variable and each point (grid cell) are represented by an average (compromise) position as well as by a position per year. When grouping the grid cells by hierarchical clustering, we used their average positions. We now consider the inertia around the average positions. The inertia in time for each grid cell showed a clear spatial pattern also (Fig. 5), where the variability is mostly located in the coastal areas and close to the limits of groups G2, G3 and G4. Such variability can be interpreted by analyzing the variability in time of the variables. The variables showing the largest variability in time (Fig. 6) are anchovy, surface salinity, sprat and water column stratification (Depot). They are characteristic of different spatial groups (Table 5) and therefore key in explaining the spatial pattern in the temporal variability (Fig. 5). These variables are correlated: salinity and sprat, and anchovy and water column stratification are opposed on MFA principal axis 1 and 2, respectively (Fig. 7). The bi-plot representation, where both variables and grid cell points are superposed (Fig. 7) allows to identify what generates the spatial pattern in the temporal variability. Surface salinity, water column stratification and sprat in 2010 and 2012, and anchovy and sprat in 2011 show largest deviations from the average pattern and are thus responsible for the inertia 
observed on the map of ecosystem structure (Fig. 5). It is noteworthy that the major source of variability lies in variables related to river plume dynamics.

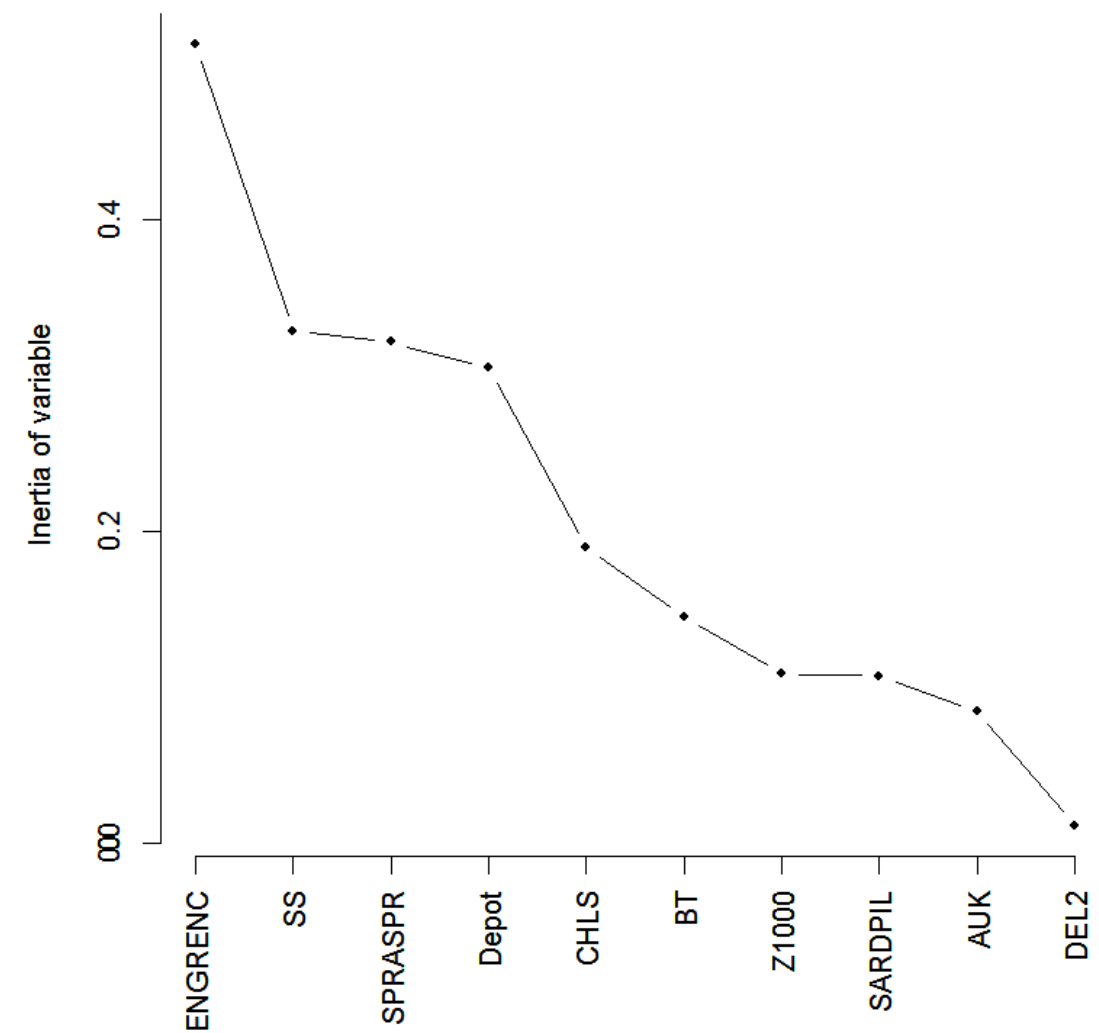

Figure 6: MFA applied on all ecosystem compartments. Inertia of the variables (Table 5) that are most correlated to the principal components. Acronyms of variables are defined in Table 1. 

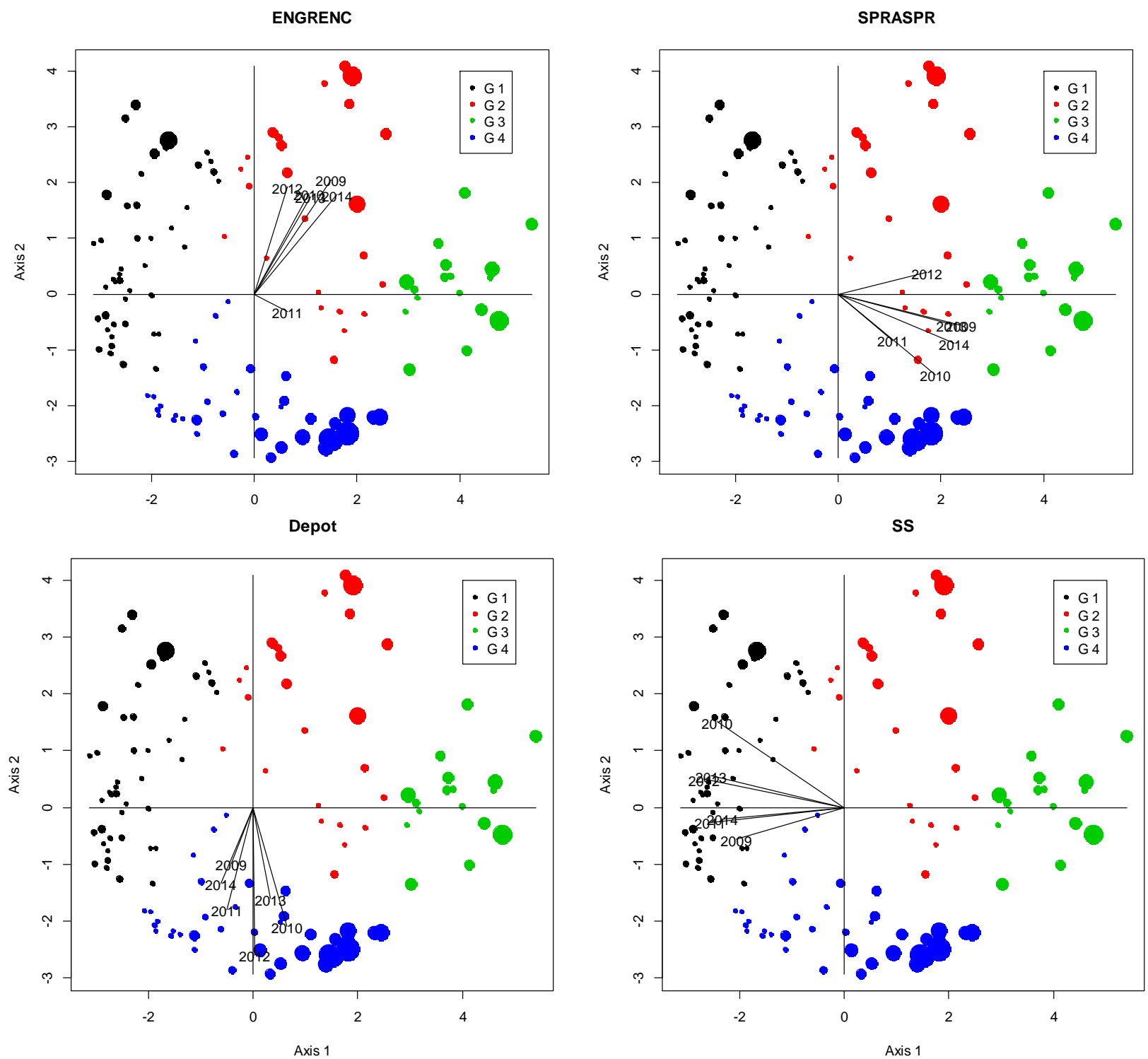

Figure 7: Bi-plot in the MFA plane (two first principal axis) of the four variables showing greatest variability in time superposed on the (spatial) grid cells. The segments represent the variable-vectors in the different years. The circles are proportional to the inertia in time around the average grid points. The colors correspond to the four groups identified by hierarchical clustering. Acronyms of variables are defined in Table 1.

\section{Discussion}

\subsection{Data and methods for ecosystem description and assessment}

Integrated survey series such as PELGAS provide end-to-end georeferenced data over large sea areas in major ecosystem compartments with defined biological resolution and spatio-temporal scale. We 
applied a generic procedure made of several steps to identify and map ecosystem spatial entities. First, the data were interpolated on a common spatial grid and organized as a time series of tables containing at each time the variables as columns and the grid cells as rows. The multi-table analysis method known as Multi-Factor Analysis (MFA) was then applied on the series of tables. This allowed a description of the correlation among the variables over space and time. Grouping the grid cells based on their relative positions in the MFA space resulted in mapping grid cells of similar state over time. We developed a procedure to select variables in each ecosystem compartment that facilitated the identification of common spatial patterns across compartments. The result of the analysis is a map of ecosystem seascapes that are consistent over the years together with a map of their interannual variability. Our analysis demonstrated the possibility of analyzing data from integrated survey series with appropriate space-time methodology to characterize and monitor ecosystem spatial structure at meso-scale over large sea areas. Survey products characterizing ecosystem spatial organization are seldom considered as yet (ICES, 2016). This study highlights the value in monitoring ecosystem spatial structure and developing indicators for their use in ecosystem assessment. The space-time analysis performed here served for ecosystem description but it could also be used for ecosystem assessment. In particular, the inertia in time measures departure from a mean or a reference state and thus can serve to assess changes in the ecosystem with defined statistical significance. For instance, Petitgas and Poulard (2009) combined MFA and decision-CUSUM methods to statistically evidence changes in spatial distributions.

\subsection{From seascapes to production systems and meta-ecosystems}

Though lower trophic level parameters are expected to vary during the survey on a shorter time scale than the survey duration, the study revealed that many parameters showed strong spatial patterns at the scale of the survey, such as gradients in bottom temperature, salinity or biomass in chlorophyll or large zooplankton. These patterns were spatially coherent with that in the higher trophic levels. Patterns in higher trophic levels corresponded to gradients in the abundance of particular species. We were thus able to map the overall coherence in the spatial organization across the ecosystem compartments. The spatial patterns identified were typically meso-scale (tens to hundreds of kilometers). Ecosystem mapping at a lower spatial resolution would perhaps be difficult to attain because of the biological resolution of the data and the space-time scale of the sampling.

The ecosystem spatial units identified are similar to seascapes (Wiens, 2005). Further, we now argue that they correspond to production systems. The four ecosystem spatial units identified agree with previous descriptions of the dynamics of hydrology and plankton in the Bay of Biscay. The river plumes from Loire and Gironde influence in terms of salinity, turbidity and nutrients the coastal and shelf waters extending to the mid-shelf as indicated by the $100 \mathrm{~m}$ isobath (Castaing et al., 1999). In 
late winter, phytoplankton blooms (diatoms) occur on mid-shelf at the distal end of the river plumes and in spring nutrients are depleted in these areas, where the microbial loop is active (Guillaud et al., 2008). In spring the nutrient-rich river plumes sustain phytoplankton production in coastal waters only. In contrast at the shelf break, the production system is different. There, incoming spring tides interact with the shelf-break topography and generate internal waves of the pycnocline, which result in regular vertical mixing and a sustained phytoplankton production. Differences between coast, midshelf and shelf-break areas was also reported for zooplankton communities (Albaina and Irigoien, 2004). In addition, Vandromme et al. (2015) evidenced larger zooplankton in northern Biscay, probably because of the seasonal evolution of stratification, the timing of phytoplankton blooms and the distribution of small pelagic fish. These production systems agree with the four groups identified and in particular the shelf-break and the coastal groups (G1 and G3). The difference between the southern and northern shelf groups (G2 and G4) could be explained by the seasonal dynamics in water warming, the timing of phytoplankton blooms and the distribution of small pelagic fish during their life cycles.

In a recent review of worldwide biological production systems that sustain fisheries, Fogarty et al. (2016) considered the consequence of different trophic pathways on fisheries production. Here the Bay of Biscay (a large marine ecosystem) is patchy with different production systems at meso-scale each having its particular temporal dynamics (Koutsikopoulos and Le Cann, 1996; Planque et al., 2004) and corresponding trophic pathways (Guillaud et al., 2008). Thus the Bay of Biscay could be seen as a meta-ecosystem (Loreau et al., 2003; Massol et al., 2011) made of connected local production systems. The major connectivity pathways could be seasonal migration patterns in the higher trophic levels and seasonal hydrodynamic regimes. The understanding of the ecology of the Bay of Biscay as a meta-ecosystem would require to identify and map the sub-units (as in the present study), but also understand their production dynamics and the connectivity between them. An ecosystem assessment would need to consider how all these elements depart from a reference situation. The present analysis defines the areas and limits of ecosystem sub-units to be considered in ecosystem assessment and management.

\subsection{Towards spatially explicit management scenarios}

The ecosystem sub-units identified related to production systems, which could be considered as elementary units for designing ecosystem-based management scenarios. Such scenarios would then need to consider the production systems that stocks visit at different seasons during their life cycles (ICES, 2010). This will require spatially explicit end-to-end models to assemble knowledge and evaluate by simulations management scenarios in space and time. Thus, in addition to ecosystem monitoring, description and assessment, integrated survey data series are also useful to validate the 
capability of models to simulate realistically spatial patterns in ecosystems (Travers-Trolet et al., 2014). Thus the importance of novel survey products based on mapping (e.g., ICES, in press), such as maps of ecosystem units as produced here. In effect, they provide information on the spatial scales and areas that need be considered.

\section{Acknowledgments}

We thank the crew of the R/V Thalassa and colleagues who joined the cruises, without which the data collection at sea and analyses in the laboratory would have been impossible, in particular Paul Bourriau, Françoise Mornet, Erwan Duhamel, Patrick Lespagnol, Patrick Grellier and Florence Sanchez from Ifremer, as well as Philippe Pineau from La Rochelle University and observers of marine megafauna from Pelagis observatory. The Pelgas integrated survey series was initiated by Jacques Massé from Ifremer. We also thank the referees who helped improve the manuscript.

\section{References}

Abdi, H., Williams, L. and Valentin, D. 2013. Multiple factor analysis: principal component analysis for multitable and multiblock data sets. WIREs Computational Statistics, 5: 149-179.

Albaina, A., and Irigoien, X. 2004. Relationships between Frontal Structures and Zooplankton Communities along a Cross-Shelf Transect in the Bay of Biscay (1995 to 2003). Marine Ecology Progress Series, 284: 65-75.

Castaing, P., Froidefond, J.-M., Lazure, P., Weber, O., Prud'homme, R. and Jouanneau, J.-M. 1999. Relationship between Hydrology and Seasonal Distribution of Suspended Sediments on the Continental Shelf of the Bay of Biscay. Deep Sea Research II, 46: 1979-2001.

Dazy, F. and Le Barzic, J.-F. 1996. L’analyse des données évolutives: méthodes et applications. Editions Technip, Paris.

Doray, M., Petitgas, P., Huret, M., Duhamel, E., Dupuy, C., Romagnan, J.-B., Spitz, J., Authier, M., Sanchez, F., Berger, L., Dorémus, G., Bourriau, P., Grellier, P. and Massé, J. Submitted. The PELGAS survey: ship-based integrated monitoring of the Bay of Biscay pelagic ecosystem. Progress in Oceanography, this issue.

Doray, M., Badts, V., Massé, J., Duhamel, E., Huret, M., Doremus, G. and Petitgas, P. 2014. Manual of fisheries survey protocols. PELGAS surveys (PELagiques GAScogne). R.INT RBE/EMH 2014-01. Ifremer' institutional repository Archimer. http://doi.org/10.13155/30259

Dray, S. and Dufour, A.-B. 2007. The ade4 package: implementing the duality diagram for ecologists. Journal of Statistical Software, 22: 1-20. https://CRAN.R-project.org/package=ade4 
Eriksen, E., Gjøsæter, H., Prozorkevich,D., Shamray, E., Dolgov, A., Skern-Mauritzen, M., Stiansen, J., Kovalev, Y. and Sunnanå, K. Submitted. From single species surveys towards monitoring of the Barents Sea ecosystem. Progress in Oceanography, this issue.

Escoffier, B. and Pagès, J. 1994. Multi factor analysis (AFMULT pack-age). Computational Statistics and Data Analysis, 18: 121-140.

Fogarty, M., Rosenberg, A., Cooper, A., Dickey-Collas, M., Fulton, E., Gutiérrez, N., Hyde, K., Kleisner, K., Kristiansen, T., Longo, C., Minte-Vera, C., Minto, C., Mosqueira, I., Osio, G., Ovando, D., Selig, E., Thorson, J. and Ye, Y. 2016. Fishery production potential of large marine ecosystems: A prototype analysis. Environmental Development, 17 (Suppl1): 211-219.

Gaertner, J.-C., Chessel, D. and Bertrand, J. 1998. Stability of spatial structures of demersal assemblages. Aquatic Living Resources, 11: 75-85.

Garcia, S., Zerbi, A., Aliaume, C., Do Chi, T. and Lasserre, G. 2003. The ecosystem approach to fisheries management. FAO Fisheries Technical Paper No. 443.

Guillaud, J.-F., Aminot, A., Delmas, D., Gohin, F., Lunven, M., Labry, C. and Herbland, A. 2008. Seasonal Variation of Riverine Nutrient Inputs in the Northern Bay of Biscay (France), and Patterns of Marine Phytoplankton Response. Journal of Marine Systems, 72: 309-19.

Huret, M., Bourriau, P., Doray, M., Gohin, F. and Petitgas, P. Submitted. Survey timing and ecosystem seasonal scheduling: assessing the observed interannual variability with application to anchovy and sardine spawning phenology in the Bay of Biscay. Progress in Oceanography, this issue.

Huret, M., Sourisseau, M., Petitgas, P., Struski, C., Léger, F. and Lazure, P. 2013. A multi-decadal hindcast of a physical-biogeochemical model and derived oceanographic indices in the Bay of Biscay. Journal of Marine Systems, 109-110: S77-S94

ICES. In press. Pelagic survey series for sardine and anchovy in ICES subareas VIII and IX - Towards an ecosystem approach. ICES Cooperative Research Report No. 332. http://ices.dk/publications/library/Pages/default.aspx

ICES. 2016. Report of the Workshop on Integrated Ecosystem Assessment methods (WKIDEA). ICES CM 2016/SSGIEA:15. http://ices.dk/publications/library/Pages/default.aspx

ICES, 2010. Life-cycle spatial patterns of small pelagic fish in the Northeast Atlantic. Cooperative Research Report No. 306. http://ices.dk/publications/library/Pages/default.aspx

Kenny A., Skjoldal, H., Engelhard, G., Kershaw, P. and Reid, J. 2009. An integrated approach for assessing the relative significance of human pressures and environmental forcing on the status of Large Marine Ecosystems. Progress in Oceanography, 81: 132-148.

Koutsikopoulos, C. and Le Cann, B. 1996. Physical processes and hydrological structures related to the Bay of Biscay anchovy. Scientia Marina, 60: 9-19. 
Kupschus, S., Schratzberger, M., Righton, D. 2016. Practical implementation of ecosystem monitoring for the ecosystem approach to management. Journal of Applied Ecology, 53: 1236-1247.

Loreau, M., Mouquet, M. and Holt, R. 2003. Meta-ecosystems: a theoretical framework for a spatial ecosystem ecology. Ecology Letters, 6: 673-679.

Massol, F., Gravel, D., Mouquet, N., Cadotte, M., Fukami, T. and Leibold, M. 2011. Linking community and ecosystem dynamics through spatial ecology. Ecology Letters, 14: 313-323

Petitgas, P., Massé, J., Beillois, P., Lebarbier, E. and Le Cann, A. 2003. Sampling variance of species identification in fisheries acoustic surveys based on automated procedures associating acoustic images and trawl hauls. ICES Journal of Marine Science, 60: 437-45.

Petitgas, P., Goarant, A., Massé, J. and Bourriau, P. 2009. Combining acoustic and CUFES data for the quality control of fish-stock survey estimates. ICES Journal of Marine Science, 66: 1384-1390.

Petitgas, P. and Poulard, J.-C. 2009. A multivariate indicator to monitor changes in spatial patterns of age-structured fish populations. Aquatic Living resources, 22: 165-171.

Planque, B., Lazure, P. and Jegou, A.-M. 2004. Detecting hydrological landscapes over Bay of Biscay continental shelf in spring. Climate Research, 28: 41-52.

Poulard, J.-C. and Léauté, J.-P. 2002. Interaction between marine populations and fishing activities: temporal patterns of landings of La Rochelle trawlers in the Bay of Biscay. Aquatic Living Resources, 15: 197-210.

Shephard, S., van Hal, R., de Boois, 1., Birchenough, S.N.R., Foden, J., O'Connor, J., Geelhoed, S.C.V., Van Hoey, G., Marco-Rius, F., Reid, D.G., Schaber, M., 2015. Making progress towards integration of existing sampling activities to establish Joint Monitoring Programmes in support of the MSFD. Marine Policy, 59: 105-111.

Travers-Trolet, M., Shin, Y.-J. and Field, J. 2014. An end-to-end coupled ROMS-N(2)P(2)Z(2)D(2)OSMOSE of the southern Benguela foodweb: parameterization, calibration and pattern-oriented validation. African Journal of Marine Science, 36: 11-29.

Vandromme, P., Nogueira, E., Huret, M., Lopez-Urrutia, A., González-Nuevo González, G., Sourisseau, M. and Petitgas, P. 2014. Springtime Zooplankton Size Structure over the Continental Shelf of the Bay of Biscay. Ocean Science, 10: 821-35.

Wiens, J. 2005. Toward a unified landscape ecology. In: Wiens, J. and Moss, M. (Eds.), Issues and perspectives in landscape ecology. Cambridge University Press, Cambridge, pp. 365-373. 
PROOCE 2017-70

Highlights

- Demonstrate how georeferenced integrated survey data series can be serve ecosystem description

- How ecosystem spatial structure can be revealed by applying Multiple Factor Analysis (MFA) on integrated survey data series

- How the same methodology also produces a map of temporal variability around the average ecosystem structure

- The understanding of the Bay of Biscay as a meta-ecosystem made of connected distinct production systems sustaining pelagic fish resources 